\title{
Adjoint analysis of the 2007 all time Arctic sea-ice minimum
}

\author{
F. Kauker, ${ }^{1,2}$ T. Kaminski, ${ }^{3}$ M. Karcher, ${ }^{1,2}$ R. Giering, ${ }^{3}$ R. Gerdes, ${ }^{2}$ and M. Voßbeck ${ }^{3}$ \\ Received 13 October 2008; revised 5 December 2008; accepted 13 January 2009; published 13 February 2009.
}

[1] The past two decades saw a steady decrease of summer Arctic sea ice extent. The 2007 value was yet considerably lower than expected from extrapolating the long-term trend. We present a quantitative analysis of this extraordinary event based on the adjoint of a coupled ocean-sea ice model. This new approach allows to efficiently assess the sensitivity of the ice-covered area in September 2007 with respect to any potential influence factor. We can trace back $86 \%$ of the ice area reduction to only four of these factors: May and June wind conditions, September 2-meter temperature, and March ice thickness. Two thirds of the reduction are determined by factors that are already known at the end of June, suggesting a high potential for an early prediction. Citation: Kauker, F., T. Kaminski, M. Karcher, R. Giering, R. Gerdes, and M. Voßbeck (2009), Adjoint analysis of the 2007 all time Arctic sea-ice minimum, Geophys. Res. Lett., 36, L03707, doi:10.1029/2008GL036323.

\section{Introduction}

[2] The ice covered area in the high latitudes has strong impact on the global energy balance, its changes contribute to the polar amplification of climate change [Serreze and Francis, 2006]. The Arctic ice-cover minimum occurs in September at the end of the melting season. This minimum extent has dropped from about 7.5 million $\mathrm{km}^{2}$ in the early 1980s to 6 million $\mathrm{km}^{2}$ in the early 2000s [Comiso et al., 2008]. In September 2007 the ice extent reached a new record minimum of 4.3 million $\mathrm{km}^{2}$ [Comiso et al., 2008; Stroeve et al., 2007]. This dramatic event received widespread media attention (e.g., http://www.sciencedaily.com/ releases/2007/08/070816133926.htm) and triggered an intense scientific debate on its causes external to the seaice ocean system. Candidates are atmospheric conditions in 2007 such as winds [Overland et al., 2008] or clear sky conditions [Schweiger et al., 2008] or oceanic conditions causing basal melting [Perovich et al., 2008; Zhang et al., 2008], including increased inflow of warm Pacific water through Bering Strait [Shimada et al., 2006]. Another hypothesis suggests a link to the ice thickness of the preceding winter [Maslanik et al., 2007].

[3] We analyze the event by means of the adjoint of the coupled ocean-sea ice model NAOSIM [Kauker et al., 2003]. Historically, the common integral measure for the ice cover has been the extent (nowadays defined as the area within the contour of $15 \%$ ice concentration) because it roughly coincides with the area that was inaccessible to whalers [de la Mare, 1997]. Ice extent is also popular,

\footnotetext{
${ }^{1}$ OASys, Hamburg, Germany.

${ }^{2}$ Alfred Wegener Institute, Bremerhaven, Germany.

${ }^{3}$ FastOpt, Hamburg, Germany.
}

Copyright 2009 by the American Geophysical Union. 0094-8276/09/2008GL036323\$05.00 because it can be observed accurately by space-borne sensors. The climatically important ice-albedo feedback, however, depends on the ice covered area, which is the surface integral over the ice concentration. For our sensitivity analysis we, hence, select as target quantity, $A$, the sea-ice area in the Arctic and sub-Arctic averaged over the period of the observed sea-ice area minimum from 11th to 24th September.

\section{Methods}

[4] The model used for the present analysis is the coupled ice-ocean model NAOSIM (North Atlantic/Arctic Ocean Sea Ice Model). NAOSIM is based on the MOM-2 model of the GFDL. The version of NAOSIM used here has a horizontal grid spacing of $0.5^{\circ}$ on a rotated spherical grid. In the vertical it is resolved by 20 levels, their spacing increasing with depth. The ocean model is coupled to a seaice model with viscous-plastic rheology. At the open boundary near $50^{\circ} \mathrm{N}$ the barotropic transport is prescribed from a coarser resolution version of the model that covers the whole Atlantic northward of $20^{\circ} \mathrm{S}$ [Koeberle and Gerdes, 2003]. The initial hydrography in January 1948 is taken from the PHC climatology [Steele et al., 2001]. The ice concentration is set to $100 \%$ where the sea-surface temperature falls below the freezing temperature and an ice thickness of $2 \mathrm{~m}$ is assumed. All other initial fields are set to zero. Starting from these initial conditions, the model is run with daily atmospheric forcing from 1948 to 2008 (NCEP/NCAR reanalysis [Kalnay et al., 1996]). The open boundary hydrography is also taken from the PHC climatology, which is as well used as a reference for a surface salinity restoring with 180 days timescale. For a more detailed description of the model see Kauker et al. [2003].

[5] NAOSIM was successfully applied in a variety of studies concerned with the North Atlantic and Arctic sea ice and ocean (see the JGR special edition "Arctic Ocean Model Intercomparison Project, Studies and Results" [Proshutinsky and Kowalik, 2007]).

[6] In mathematical terminology, tangent linear and adjoint models evaluate the derivative of a function that is defined through the underlying model. This function takes a particular combination of the model's process parameters, initial and boundary conditions as input (independent variables) and has as output (dependent variables or target quantities) a set of quantities that can be simulated by the model.

[7] Automatic differentiation is a procedure which generates source code for evaluation of derivatives from the code of the underlying model. The model code is decomposed into elementary functions (such as,,$+- \sin (\cdot))$, for which the derivative (local Jacobian) is easy to derive. The derivative of the composite function is then constructed via the chain rule as the product of all local Jacobians. According to the associative law, this multiple matrix product can be 


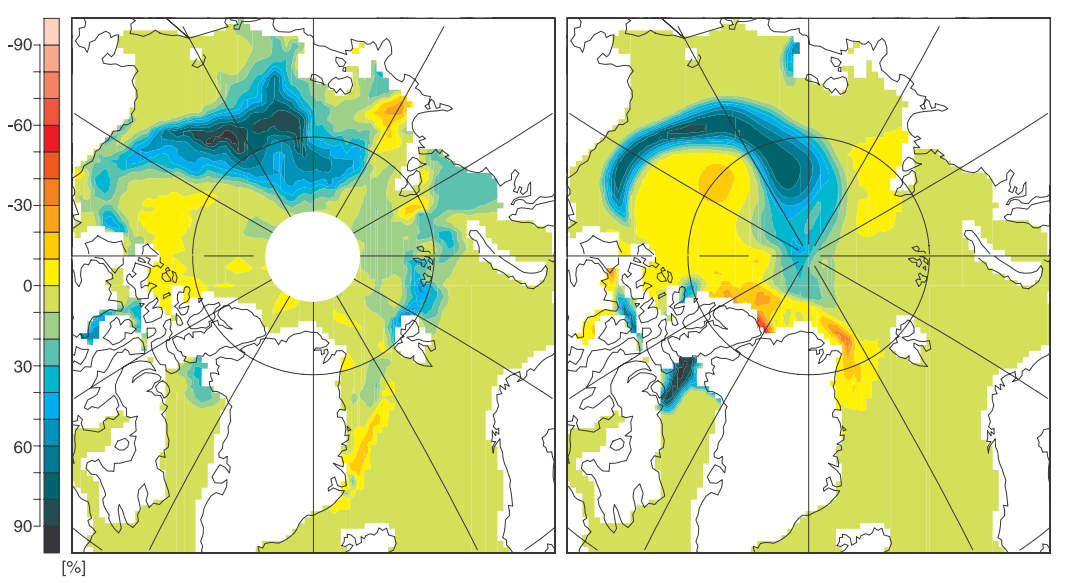

Figure 1. The difference between the mean September 2005 and 2007 ice concentration [\%] calculated from satellite (left) observations [Comiso et al., 2008] and (right) simulations.

evaluated in arbitrary order without changing the result. The tangent linear model does this evaluation in the same order as the function is evaluated, which is called forward mode of automatic differentiation. The adjoint model uses exactly the opposite order, which is called reverse mode of automatic differentiation.

[8] It is easy to see that the computational cost of the forward mode is proportional to the number of independent variables and almost independent of the number of dependent variables. By contrast, the computational cost of the reverse mode is proportional to the number of dependent variables and independent of the number of the independent variables. Hence, the adjoint is an ideal tool to quantify the sensitivity of a small set of target quantities with respect to a change in a larger number of independent variables. Construction of adjoint code is described by Giering and Kaminski [1998] and Marotzke et al. [1999], who also present an application to a global model of the general ocean circulation. Errico [1997] gives an overview on adjoints and their applications (including data assimilation and stability analysis) from an atmospheric perspective. For generation of the derivative code we use the automatic differentiation tool Transformation of Algorithms in Fortran (TAF) [Giering and Kaminski, 1998]. All derivative code has been verified against finite difference approximations via multiple model runs.

\section{Results}

[9] To produce reference values of the sea-ice area we run NAOSIM from 1948 to spring 2008. In this simulation, the ice extent minimum in September 2007 is about 1.3 million $\mathrm{km}^{2}$ lower than the previous record minimum of 2005 . This is very close to the satellite based estimate [Comiso et al., 2008]. The simulated ice area in September 2007 is 0.90 million $\mathrm{km}^{2}$ below the September 2005 ice area.

[10] Figure 1 displays the difference between September 2005 and September 2007 ice concentrations as derived from satellite observations (Figure 1 (left)) and as simulated by the model (Figure 1 (right)). A sickle of higher sea-ice concentration in September 2005 as compared to September 2007 extends from the Chukchi borderland to the Lomonosov
Ridge. The model captures the general structure, with some regional differences.

[11] We analyse the period from March to September 2007. A single run of the adjoint covering this period efficiently computes the sensitivity of our target quantity $A$ with respect to the following input quantities on the full model grid (forming the vector of independent variables, $x$ ): the surface boundary conditions, namely the wind stress, scalar wind, 2-meter temperature, dew-point temperature, cloud cover, and precipitation as well as the initial values (at 1st of March 2007) of the ocean baroclinic velocities, ocean temperatures, ocean salinities, barotropic streamfunction, ice thickness, ice concentration, snow depth, and ice drift. In this set-up the size of the vector of independent variables well exceeds a million, a size prohibitive for ordinary sensitivity experiments.

[12] The adjoint sensitivities provide a linear approximation of the target quantity around a reference vector of input variables, $x_{0}$ :

$$
A(x) \approx A\left(x_{0}\right)+\frac{d A}{d x}\left(x_{0}\right)\left(x-x_{0}\right)
$$

[13] Equation (1) yields the model's first order response to a perturbation of $x$. We use equation (1) to decompose [see Kaminski et al., 1996, 1999] the change in the target quantity into the contributions from the individual components of the input vector, $x$ :

$$
A(x)-A\left(x_{0}\right) \approx \sum_{i} \frac{\partial A}{\partial x_{i}}\left(x_{0}\right)\left(x_{i}-x_{0, i}\right)
$$

A component $x_{i}$ can be, for instance, the initial temperature at a particular grid cell or the cloud cover over a particular surface grid cell in a particular time interval. For each component, its contribution is the partial derivative weighted by the size of the perturbation.

[14] We take the reference vector, $x_{0}$, from the year 2007. To understand why 2007 was so unique we compare 2007 with 2005, the former minimum year, i.e., the perturbations used in equation (2) are the 2005-2007 differences for each component of the input vector. 
a)

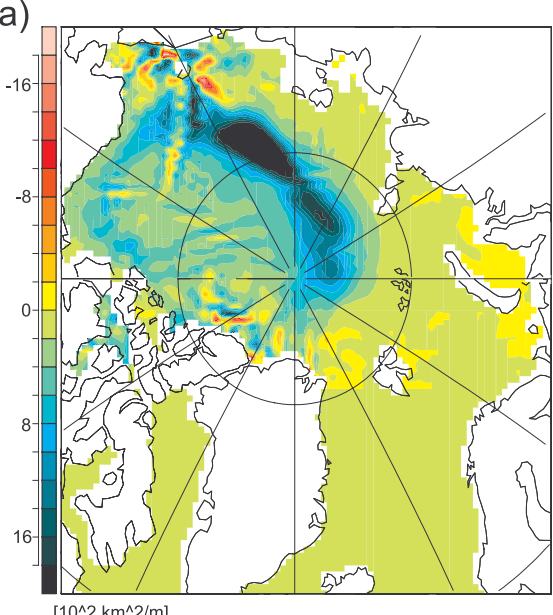

$\left[10^{\wedge} 2 \mathrm{~km} \wedge 2 / \mathrm{m}\right]$

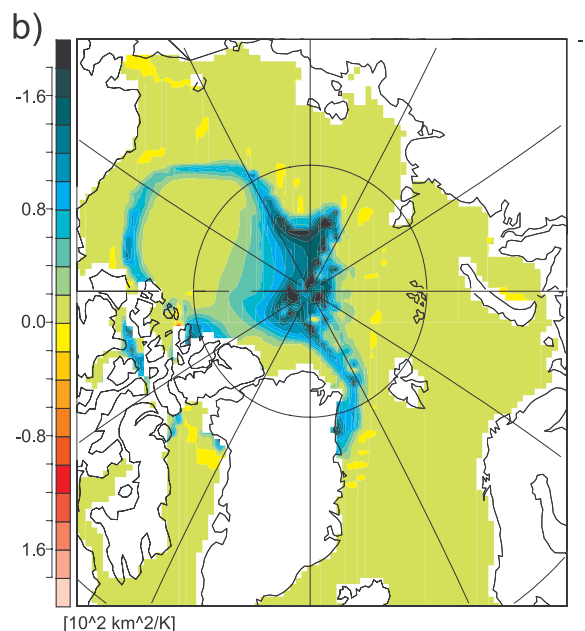

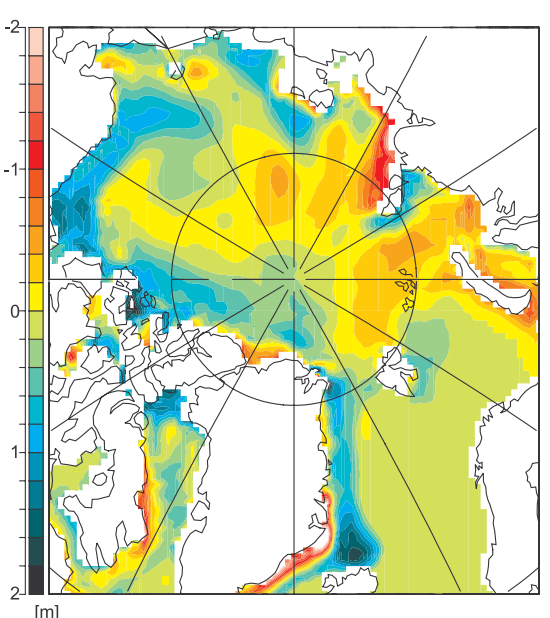

$[\mathrm{m}]$

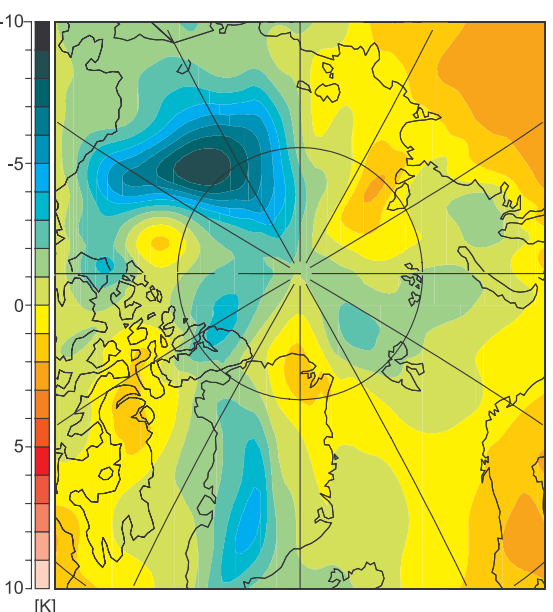

$[\mathrm{K}]$

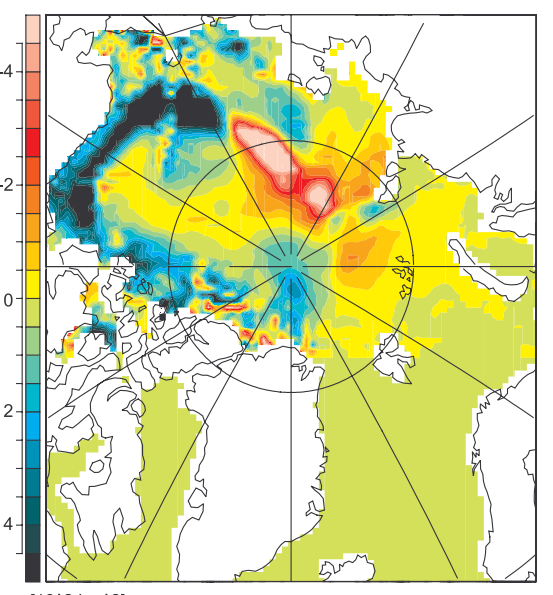

$\left[10^{\wedge} 2 \mathrm{~km}^{\wedge} 2\right]$

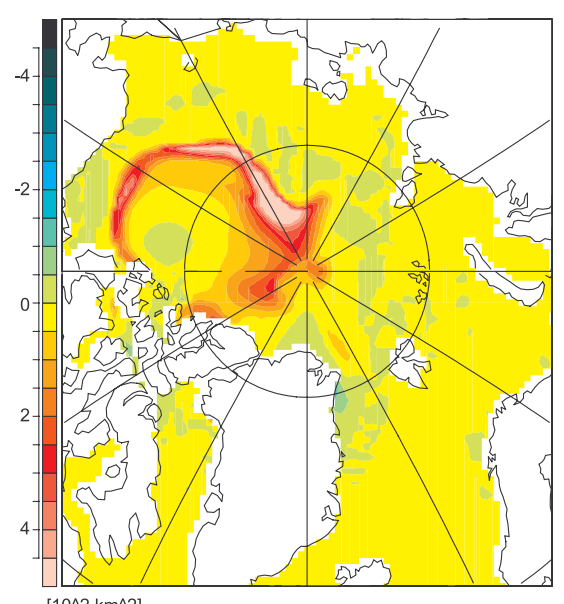

Figure 2. (a) The sensitivity $\left[10^{2} \mathrm{~km}^{2} / \mathrm{m}\right]$ of the total ice area in mid September 2007 with respect to the initial sea-ice thickness on (left) the 1st of March 2007, (middle) the 2005-2007 difference (perturbation) in the initial ice thickness [m], and (right) the product of the sensitivity and the perturbation in each grid cell $\left[10^{2} \mathrm{~km}^{2}\right]$. (b) The sensitivity $\left[10^{2} \mathrm{~km}^{2} / \mathrm{K}\right] \mathrm{of}$ the total ice area in mid September 2007 with respect to (left) the 2-meter temperature in September, (middle) the perturbation in the 2-meter temperature $[\mathrm{K}]$, and (right) the product of the sensitivity and the perturbation in each grid cell $\left[10^{2} \mathrm{~km}^{2}\right]$.

[15] The adjoint of NAOSIM produces more than 100 horizontal maps displaying the sensitivities of $A$ with respect to all surface boundary conditions and the initial values of all model variables on all layers. We display the sensitivities of $A$ with respect to the initial sea-ice thickness and the 2-meter temperature in September (Figure 2 (left)). Over almost the whole central Arctic the sensitivity with respect to the initial ice thickness is positive (with largest values over the Chukchi plateau): an increase of ice thickness at the 1st of March 2007 increases $A$, the sea-ice area in mid September 2007. The sensitivity with respect to the September 2-meter temperature is almost everywhere negative: an increase of the 2-meter temperature decreases $A$.

[16] For initial ice thickness north of Alaska and over the Chukchi plateau positive sensitivity and positive perturbation yield large positive contribution to the sum of equation (2) (Figure 2a (right)). This means that in these areas the larger initial ice thickness at the first of March 2005 as compared to 2007 increases the total ice area in September 2005 relative to September 2007. Over the Makarov basin less ice thickness at the first of March 2005 as compared to 2007 reduces the ice area in September 2005 relative to September 2007. For the September 2-meter temperature Figure $2 \mathrm{~b}$ (right) shows positive contributions almost over the whole model domain because almost everywhere over the ocean September 2005 was colder than September 2007 (Figure 2b (middle)). A sickle of large positive contributions is surrounding the central Beaufort Sea. Note that in this case the largest contributions are not located at the position of the largest perturbations but further north owing to larger sensitivity at that location.

[17] There are various ways for condensing the rich suite of sensitivity information. Figure 3 displays, in spatially aggregated form, the contributions of the monthly averaged surface boundary conditions and all initial fields. The largest contributions stem from the following four high impact fields: the windstress in May and June, the 2-meter temperature in September, and the initial sea-ice thickness. The sum of their contributions amounts to about $90 \%$ of the ice area difference between Septembers 2005 and 2007. 


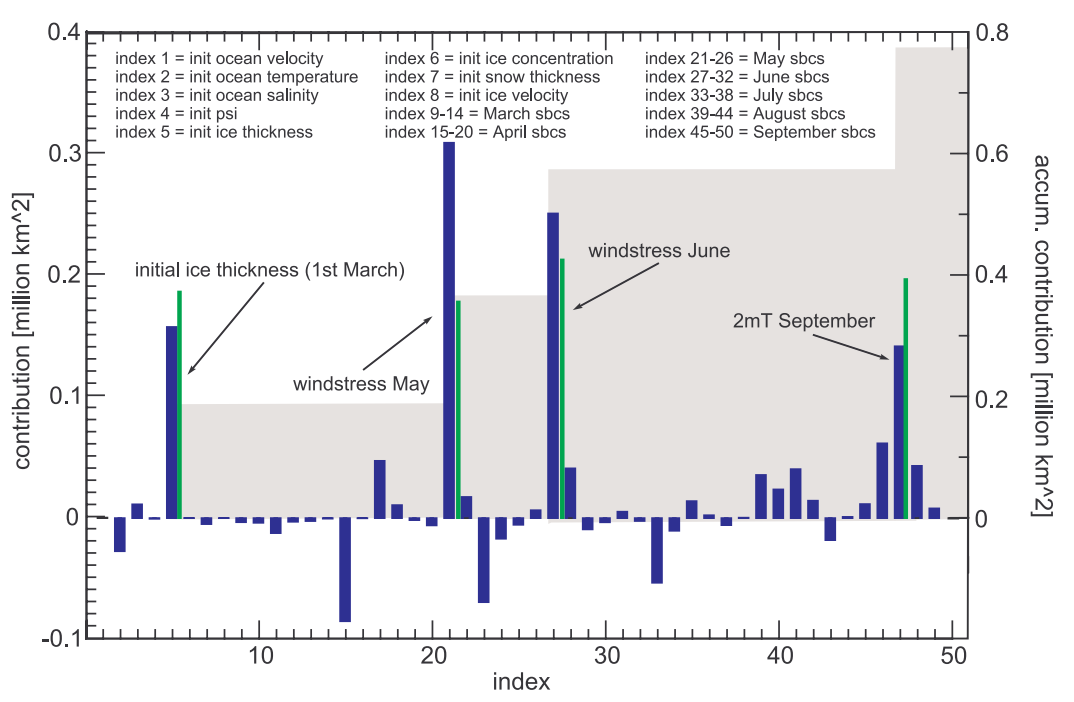

Figure 3. The contribution to the difference in ice area between September 2005 and September 2007 according to the adjoint analysis (blue bars, left legend). The monthly surface boundary conditions are listed in the following order: wind stress, scalar wind, 2-meter temperature, dew-point temperature, cloud cover, precipitation. The contribution of the ocean baroclinic velocities, the ocean temperature, and the salinities are integrated over the ocean layers. The green bars display the corresponding values from the simulations with the four high impact fields from the non-linear model. The grey bars (right legend) display the contributions of the four high impact fields accumulated over time.

[18] Our adjoint analysis can only approximate these contributions, because it relies on a linearization of the model, which misses the higher-order terms in the Taylor series expansion of equation (1). Therefore, we test the results of the adjoint analysis by a set of runs with our original non-linear model. As reference we use our above described reference run from March 2007 to September 2007, which we denote by R2007. A second run (denoted R2005) with all independent variables perturbed to their 2005 values would just repeat the period from March to September 2005 of our long reference integration from 1948 to 2007 that produced the difference map on Figure 1 (right). Now, for each of our test runs we perturb only one of the four high impact fields. For instance, to test the effect of the May wind stress, we replace the 2007 May wind stress by the 2005 May wind stress. The tests reveal that the adjoint analysis identified the high impact fields correctly (green bars in Figure 3). The adjoint analysis overestimates the contribution of the May and June windstress, underestimates the contribution of the 2-meter temperature in September and the contribution of the initial ice thickness. Summing up the four contributions we find that they capture $86 \%\left(0.78\right.$ million $\left.\mathrm{km}^{2}\right)$ of the change in $A$.

[19] In contrast to the linearized model, in the non-linear model the superposition of the individual contributions does not necessarily equal the total change in the target quantity. In a final test run we, thus, perturb all four high impact fields simultaneously. This experiment also captures $86 \%$ of the change in $A$, as the superposition of the individual contributions.

[20] The test runs with the non-linear model also provide the spatial structure of the September ice cover. Figure S1 (see auxiliary material) displays for each of the test runs the 2007 ice concentration difference to R2007. ${ }^{1}$ It is interesting

\footnotetext{
${ }^{1}$ Auxiliary materials are available in the HTML. doi:10.1029/ 2008GL036323.
}

to compare these maps with the full R2005-R2007 difference displayed in Figure 1 (right). Changing only the four high impact fields to their 2005 values yields indeed a very similar spatial structure.

\section{Conclusions}

[21] We now address the mechanisms behind the respective contributions to the change in the ice area $A$. The effect of the September 2-meter temperature on $A$ via the surface melting is direct (see Figure 2). The effect of the May and June windstress on $A$ is indirect and thus requires the analysis of the corresponding perturbation run (see auxiliary material).

[22] Revisiting our initial list of hypotheses for the origin of the extreme event, our analysis shows that processes such as a reduced cloud cover ("open sky conditions") or the inflow of more warm Pacific Water through Bering Strait have only a minor effect on the 2007 ice cover. Our atmospheric forcing data (especially cloud cover and precipitation) are known to be biased over the Arctic [Bromwich et al., 2007]. However, we expect systematic errors to cancel out at least partly, because our study is based on 2005-2007 differences.

[23] It is worth recapitulating the key role of the adjoint analysis for our study. Although we used the non-linear model to verify and understand the mechanisms behind the 2007 event, it was the adjoint that indicated the origin of the event in terms of time, location and physical quantity. Note that our analysis takes an ocean sea-ice perspective on the Arctic and does not include feedback loops via the atmosphere. Links between the surface boundary conditions through atmospheric dynamics are external and the contributions of the boundary conditions specified independently. For instance, even though the atmosphere links wind to temperature, we see a low contribution of the windstress 
from July to September but a high contribution of $2 \mathrm{~m}$ temperature in September.

[24] We can also cumulate the contributions to the target along the temporal axis (Figure 3). The ice thickness at the first of March determines about 20\% of the September ice area. At the end of June 2007 about $66 \%$ of the ice area change in September was determined. This shows the increase of the predictability of the ice area minimum with time. Economy can benefit from this high predictability, for instance for ship routing. Unfortunately, rather than for ice concentration there are no area-wide observations of ice thickness. This situation will improve with the integrated Arctic observing system that is currently being set up. Variational assimilation systems will exploit the rich suite of observational data streams to reduce uncertainties in the initial conditions such as ice thickness.

[25] Acknowledgments. This study was funded by the DAMOCLES project (project 018508), financed by the European Union in the 6th Framework Programme for Research and Development.

\section{References}

Bromwich, D. H., R. L. Fogt, K. I. Hodges, and J. E. Walsh (2007), A tropospheric assessment of the ERA-40, NCEP, and JRA-25 global reanalyses in the polar regions, J. Geophys. Res., 112, D10111, doi:10.1029/2006JD007859.

Comiso, J. C., C. L. Parkinson, R. Gersten, and L. Stock (2008), Accelerated decline in the Arctic sea ice cover, Geophys. Res. Lett., 35, L01703, doi:10.1029/2007GL031972.

de la Mare, W. (1997), Abrupt mid-twentieth-century decline in Antarctic sea-ice extent from whaling records, Nature, 389, 57-60.

Errico, R. M. (1997), What is an adjoint model?, Bull. Am. Meteorol. Soc., $78,2577-2591$

Giering, R., and T. Kaminski (1998), Recipes for adjoint code construction, ACM Trans. Math. Software, 24, 437-474

Kalnay, E., et al. (1996), The NCEP/NCAR 40-year reanalysis project, Bull. Am. Meteorol. Soc., 77, 437-471.

Kaminski, T., R. Giering, and M. Heimann (1996), Sensitivity of the seasonal cycle of $\mathrm{CO}_{2}$ at remote monitoring stations with respect to seasonal surface exchange fluxes determined with the adjoint of an atmospheric transport model, Phys. Chem. Earth, 21, 457-462.

Kaminski, T., M. Heimann, and R. Giering (1999), A coarse grid threedimensional global inverse model of the atmospheric transport: 1 . Adjoint model and Jacobian matrix, J. Geophys. Res., 104, 18,535-18,553.
Kauker, F., R. Gerdes, M. Karcher, C. Kberle, and J. L. Lieser (2003), Variability of Arctic and North Atlantic sea ice: A combined analysis of model results and observations from 1978 to 2001, J. Geophys. Res., 108(C6), 3182, doi:10.1029/2002JC001573.

Koeberle, C., and R. Gerdes (2003), Mechanisms determining the variability 2003: Mechanisms determining the variability of Arctic sea ice conditions and export, J. Clim., 16, 2843-2858.

Marotzke, J., R. Giering, K. Q. Zhang, D. Stammer, C. Hill, and T. Lee (1999), Construction of the adjoint MIT ocean general circulation model and application to Atlantic heat transport sensitivity, J. Geophys. Res., 104, 29,529-29,547.

Maslanik, J. A., C. Fowler, J. Stroeve, S. Drobot, J. Zwally, D. Yi, and W. Emery (2007), A younger, thinner Arctic ice cover: Increased potential for rapid, extensive sea-ice loss, Geophys. Res. Lett., 34, L24501, doi:10.1029/2007GL032043.

Overland, J., J. Turner, J. Francis, N. Gillett, G. Marshall, and M. Tjernström (2008), The Arctic and Antarctic: Two faces of climate change, Eos Trans. $A G U, 89(19)$, doi:10.1029/2008EO190001.

Perovich, D. K., J. A. Richter-Menge, K. F. Jones, and B. Light (2008), Sunlight, water, and ice: Extreme Arctic sea ice melt during the summer of 2007, Geophys. Res. Lett., 35, L11501, doi:10.1029/2008GL034007.

Proshutinsky, A., and Z. Kowalik (2007), Preface to special section on Arctic Ocean Model Intercomparison Project (AOMIP) Studies and Results, J. Geophys. Res., 112, C04S01, doi:10.1029/2006JC004017.

Schweiger, A. J., J. Zhang, R. W. Lindsay, and M. Steele (2008), Did unusually sunny skies help drive the record sea ice minimum of 2007?, Geophys. Res. Lett., 35, L10503, doi:10.1029/2008GL033463.

Serreze, M., and J. Francis (2006), The Arctic amplification debate, Clim. Change, 76, 241-264.

Shimada, K., T. Kamoshida, M. Itoh, S. Nishino, E. Carmack, F. McLaughlin, S. Zimmermann, and A. Proshutinsky (2006), Pacific Ocean inflow: Influence on catastrophic reduction of sea ice cover in the Arctic Ocean, Geophys. Res. Lett., 33, L08605, doi:10.1029/2005GL025624.

Steele, M., R. Morley, and W. Ermold (2001), PHC: A global ocean hydrography with a high-quality Arctic Ocean, J. Clim., 14, 2079-2087.

Stroeve, J., M. M. Holland, W. Meier, T. Scambos, and M. Serreze (2007), Arctic sea ice decline: Faster than forecast, Geophys. Res. Lett., 34, L09501, doi:10.1029/2007GL029703.

Zhang, J., R. Lindsay, M. Steele, and A. Schweiger (2008), What drove the dramatic retreat of arctic sea ice during summer 2007?, Geophys. Res. Lett., 35, L11505, doi:10.1029/2008GL034005.

R. Gerdes, Alfred Wegener Institute, Bussstr. 24, D-27570 Bremerhaven, Germany.

R. Giering, T. Kaminski, and M. Voßbeck, FastOpt, Schanzenstr. 36, D-20357 Hamburg, Germany.

M. Karcher and F. Kauker, OASys GmbH, Schanzenstr. 36, D-20357 Hamburg, Germany. (frank@oasys-research.de) 